\title{
Evaluation of Selected Recycling Curricula: Educating the Green Citizen
}

\author{
SALLY BOERSCHIG and RAYMOND DE YOUNG
}

\begin{abstract}
The authors reviewed past research in environmental education and identified eight variables as strong predictors of conservation behavior change: action skills, knowledge of action strategies, knowledge of the issue, attitudes, locus of control, personal responsibility, sensitivity, and social norms. Using these eight variables, they reviewed 14 solid waste curricula from various programs around the country. The resulting scores demonstrated that solid waste curricula focus mainly on knowledge and include, to a lesser extent, attitude change and action strategies. The authors suggest reasons for the omission of action skills, locus of control, personal responsibility, sensitivity, and social norms and make recommendations to improve the contribution education can make toward mitigating the solid waste crisis and promoting waste-reducing behaviors.
\end{abstract}

$\mathrm{T}$ he generation of municipal solid waste continues to increase. The 158 million tons of municipal solid waste generated in 1988 is expected to grow to 193 million tons by 2000 . Despite efforts to promote alternative practices, landfilling remains the predominant means of managing the nation's waste.

In response, federal, state, and local governments are redoubling their waste reduction efforts. Programs are more integrated than in the past; they combine source reduction, reuse, and recycling (Office of Technology Assessment, 1989) and focus on changing individual citizens' behavior toward solid waste. These activities entail changing purchasing, consumption, and disposal practices.

Sally Boerschig recently received her masters degree in environmental education. Raymond De Young is a professor of conservation behavior at the University of Michigan.
One avenue to changing behavior is through education. Recent state recycling legislation has begun to include specific educational goals. Texas has passed legislation that expands environmental education opportunities. Oregon's recycling law now includes recycling education as an element of the state's mandated common education curriculum (Powell, 1991). Illinois has mandated solid waste curricula in the schools to "help students gain an understanding of the serious nature of the solid waste problem ... and to discover ways that they can be part of the solution" (Illinois Department of Natural Resources, 1990). The San Francisco School District's curriculum "presents information students will need to take responsibility for their personal garbage disposal habits" (City and County of San Francisco's Solid Waste Management Program, 1987). Minnesota curricula states that "studying about" solid waste is not enough, and that the students must make a difference "in determining a future where we are in balance with all of our resources" (The Minnesota Environmen- 
tal Education Board's Metro Regional Environmental Education Council, 1990).

One task of environmental educators is to teach young people about the importance of achieving high waste reduction because they will eventually make household and administrative decisions that will affect the consumption of resources and the generation of solid waste. Our youth are also in the process of forming values and habits that are easier to mold than to change and consequently, are more accessible to educational strategies. In addition, many environmental practitioners view them as agents for change. For example, after learning the fundamentals of recycling, children may go home and share the principles with their families and others.

Environmental educators must evaluate whether the current curricula can promote waste-reducing behavior. They need to determine which educational variables promote this behavior. Traditionally, educators believed that knowledge increases awareness, and that with increasing knowledge and awareness one would become motivated to act in an environmentally responsible manner (Hungerford \& Volk, 1990). The effectiveness of this approach, however, has come into question by education experts, psychologists, sociologists, and political scientists.

Currently, there are several models that contain variables that are thought to promote environmentally responsible behavior. The variables from these models were used jointly to evaluate current solid waste curricula. The goal was to determine how effective each curriculum is in promoting behavioral changes with regard to solid waste.

\section{Method}

Analysis of the existing models of environmental behavior revealed the following eight variables: Knowledge of the issue, Knowledge of action strategies, Knowledge of action skills, Attitudes, Locus of control, Personal responsibility, Sensitivity, and Social norms.

The first six were derived from the Hines model of environmentally responsible behavior (Hines et al., 1986). Hines et al. meta-analyzed 128 studies that had empirical evidence on promoting environmentally responsible behavior. The meta-analysis identified three categories of variables: cognitive (knowledge of the issue), psychosocial (including attitudes, personal responsibility, and locus of control), and situational. Hines also included action strategies and action skills because concurrent research had suggested the usefulness of various classroom approaches in achieving a desired environmentally responsible behavior (Hungerford et al., 1985). These classroom approaches employed discussions of alternative issues, development of issue investigation skills, environmental problem-solving skills, values discussions, and action-taking skills.
Because educators are unable to directly influence factors such as economics in the classroom, we eliminated the variable for situational factors. A related aspect, social norms, was included as a separate critiquing variable because of education's ability to influence norms, at least indirectly. Finally, we included sensitivity because of evidence that suggests sensitivity toward the general environment is a "strong predictor of environmentally responsible behavior" (Hungerford et al., 1985; Sia et al., 1985).

We assessed each of the eight evaluation variables in the following way:

Knowledge of the issue. Knowledge of the issue encapsulates environmental education's traditional behavioral change model mentioned above. Clearly, solid waste issues are complex and multi-faceted. The depth of knowledge can be expanded and built upon through schooling.

Knowledge of action strategies. The fundamental solutions for the solid waste problem are concisely stated in the three Rs: reduce, reuse, and recycle. These must include strategies for specific implementation. Merely stating that recycling is an alternative to landfilling waste was evaluated as insufficient. To score positively on the knowledge of action strategies, the activity must have addressed how to recycle by including procedural knowledge (De Young, 1988-1989). For instance, an activity that discussed specific ways to recycle paper in the classroom received a positive score.

Knowledge of action skills. The distinction between action strategies and skills centers on behavior. Action skills engage the students in the actual strategy and/or develop the skills necessary to competently and confidently carry out the action. If an activity culminated in a classroom paper recycling project or directed students to use the back sides of their old papers for assignments, then it received a positive score for action skills.

Attitudes. Hungerford et al. (1985) defined an attitude as "a complex mental construct (perception) which emerges out of an integration of an individual's belief and value systems." Thus, attitudes differ from knowledge in that they deal with the affective domain (Iozzi, 1989a, 1989b). Recent research suggests that contrary to the traditional behavior change model, knowledge is a necessary but insufficient instrument of change (Braun et al., 1987). Activities that received a positive score for attitudes examined, analyzed, or discussed values or beliefs toward reuse, conservation, source reduction, recycling, or some other facet of the solid waste problem.

Locus of control. Hines et al. (1986) described locus of control as

an individual's perception of whether or not he or she has the ability to bring about change through his or her own 
behavior. The concept is based on the belief that some individuals do not attempt to bring about change because they attribute change to chance or to powerful others (e.g., God, parents, government) rather than to their own behaviors.

If individuals believe they have the skills to accomplish recycling, they are more likely to attempt recycling because they are confident of the success of their efforts. Education may not be able to directly develop an internal or positive locus of control. However, research indicates that teaching citizenship action skills can improve locus of control (Hungerford \& Volk, 1990). The knowledge of action strategies and actual use of these skills in the classroom may result in a motivating sense of competence and confidence.

The actions themselves, however, may not affect one's locus of control. Within the construct of a certain behavior, one must come to appreciate the potential effect of one's individual action. Therefore, recycling in the classroom would not necessarily improve locus of control with respect to solid waste issues unless the student was aided in relating his or her individual behavior to the solid waste crisis. As such, activities that clearly linked a student's behavior (individually or within a group) with making a change received a positive score for locus of control.

Personal responsibility. Personal responsibility suggests a personal obligation or sense of duty to carry out an action (i.e., a responsibility to recycle or save resources). Included with the personal responsibility variable is a sense of personal investment. Hungerford and Volk (1990) describe this as identifying strongly with an issue because one has a proprietary interest in it. This suggests that if one understands the human involvement in waste disposal or nutrient cycles, then one will feel a responsibility to act in what would be his or her best interest (i.e., recycle and source reduce). As an educational variable, personal responsibility or investment shows up in those activities that portray the solid waste issue, not as society's problem, but as each individual's problem. This interest could be economic or environmental, but it must be presented as being of a personal nature to receive a positive score.

Sensitivity. The sensitivity variable refers to a "respect for ecological integrity and a belief that humans must somehow live in ecological harmony with the natural environment" (Hungerford et al., 1985). We defined sensitivity as distinct from attitudes in its level of specificity. The attitude variable focuses on specific aspects of solid waste, whereas sensitivity is a generic concern for the general environment. Exposure to very pristine or very degraded environments as well as "quality" outdoor experiences presumably lead to increased sensitivity. Activities that received a positive score for sensitivity were those that involved field trips to environ- ments or activities that demonstrated the unsettling impact human interventions are having on the environment.

Social norms. Social norms have been isolated as a variable to behavior change. It is our opinion that the classroom is a place where social norms can be both created and reinforced daily. We defined social norm activities as those that reinforce how pervasive recycling or source reduction is in our society, for example, decorating the halls of a school with recycling posters. This and similar activities that emphasized the social aspects of recycling or source reduction scored positively on the evaluations.

\section{Selection of Curricula}

Solid waste curricula were identified as candidates for evaluation if they (a) included a kindergarten through Grade 6 focus, (b) were designed to serve as an educational resource for public school teachers, (c) were currently being used, and (d) were available for use by others. We selected 14 curricula from around the country.

We reviewed each activity within each curricula for each of the eight evaluation variables. If the activity fulfilled the requirement of that variable, we assigned it a positive score. We then tallied the scores for the entire curriculum by each evaluation variable.

\section{Results and Discussion}

The scoring of the 14 curricula is shown in Table 1. The table highlights those variables in which the curricula scored 5 or more points and identifies those that scored at least 1 point for each of the eight evaluation variables.

Most of the solid waste curricula focused on the recognition of a problem. However, Hungerford and Volk (1990) have suggested that more than a recognition of the problem is needed for knowledge to be an effective variable in changing behavior. The knowledge must be an in-depth understanding of the issue. Although most curricula scored high for including knowledge components, many of the scores may be misleading because we did not evaluate for in-depth understanding. The most common knowledge themes included refuse amount and composition, recycling and its processes, litter, packaging, composting, and other disposal methods. Missing were discussions of the practices or attitudes that thwart recycling or source reduction initiatives, a critical assessment of the need for packaging, the risks associated with traditional disposal methods, or even an understanding of why trash is generated at all. Knowledge in these contexts would enhance an in-depth understanding and thus achieve the end goal of the curricula: to foster responsible solid waste behavior.

The knowledge of action strategies was the next main focus of the curricula. Strategies were usually discussed during the activity with a question such as "What could 
TABLE 1.-Evaluation Scores for Each Curriculum

\begin{tabular}{|c|c|c|c|c|c|c|c|c|}
\hline Name of curriculum & $\begin{array}{l}\text { Action } \\
\text { skills }\end{array}$ & $\begin{array}{l}\text { Action } \\
\text { strategies }\end{array}$ & $\begin{array}{l}\text { Knowledge } \\
\text { of issues }\end{array}$ & Attitudes & $\begin{array}{l}\text { Locus of } \\
\text { control }\end{array}$ & $\begin{array}{l}\text { Personal } \\
\text { responsibility }\end{array}$ & Sensitivity & $\begin{array}{l}\text { Social } \\
\text { norms }\end{array}$ \\
\hline A-Way With Waste ${ }^{a, b}$ & 6 & 26 & 52 & 4 & 1 & 2 & 1 & 2 \\
\hline Classroom Activities & 3 & 8 & 18 & 4 & 1 & 1 & 2 & 0 \\
\hline Conserving Classroom & 2 & 8 & 16 & 2 & 0 & 0 & 0 & 0 \\
\hline Don't Waste Waste & 1 & 3 & 12 & 1 & 0 & 0 & 0 & 0 \\
\hline $\begin{array}{l}\text { 4th R Recycling } \\
\text { Curriculum }\end{array}$ & 5 & 11 & 19 & 10 & 3 & 1 & 3 & 1 \\
\hline $\begin{array}{l}\text { Here Today, Here } \\
\text { Tomorrow }^{\mathrm{a}}\end{array}$ & 1 & 7 & 24 & 7 & 1 & 3 & 1 & 2 \\
\hline $\begin{array}{l}\text { Let's Put Waste in } \\
\text { Place }\end{array}$ & 4 & 8 & 18 & 2 & 1 & 2 & 0 & 1 \\
\hline $\begin{array}{l}\text { Litter Control, } \\
\text { Waste Management }\end{array}$ & 2 & 5 & 12 & 2 & 1 & 0 & 1 & 0 \\
\hline Recycle Alaska & 1 & 5 & 21 & 2 & 0 & 2 & 3 & 1 \\
\hline Resource Recovery & 1 & 1 & 13 & 1 & 0 & 0 & 0 & 0 \\
\hline $\begin{array}{l}\text { Solid Waste Activity } \\
\text { Packet }\end{array}$ & 2 & 4 & 8 & 2 & 0 & 0 & 1 & 0 \\
\hline Solution to Pollution & 2 & $\mathbf{5}$ & 9 & 3 & 1 & 2 & 0 & 3 \\
\hline $\begin{array}{l}\text { Super Saver } \\
\text { Investigator }\end{array}$ & 7 & 16 & 57 & 6 & 0 & 2 & 2 & 1 \\
\hline Waste Away & 5 & 21 & 33 & 4 & 2 & 5 & 4 & 5 \\
\hline
\end{tabular}

Note. Numbers in boldface type denote a score greater than or equal to 5 .

aDenotes a curriculum that scored at least 1 for every evaluation variable.

'Only activities designated for K-6 grades were evaluated from this K-12 grade curriculum.

you do to reduce the amount of refuse you make?" (Illinois Department of Natural Resources, 1990). Another problem associated with the action strategy activities was that suggestions were often given without providing appropriate procedures. For instance, one activity directed students to write to their congressional representatives but failed to instruct them on what to write or how one goes about preparing such a letter.

Attitudes, locus of control, personal responsibility, sensitivity, and social norms all scored relatively low across all 14 curricula evaluated. Attitudes may be systematically neglected because schools stay away from the affective domain (Iozzi, 1989a, 1989b). Locus of control was also conspicuously absent. An example of an activity pertaining to locus of control would be to have students calculate what the results would be if the whole school recycled all their paper, and then have them initiate a recycling program in the classroom. Hearing and visually interpreting the number of trees saved and the amount of energy saved from one's individual effort is certainly a confidence-building concept and a possible catalyst for change. Several of the curricula instructed students to calculate how much solid waste their families generate, yet few activities had students look at their individual waste generation. Even fewer addressed the solutions (i.e., behavior change) as a responsibility of each individual. We speculate that this reflects a general reluctance to teach individual responsibility for the problems of solid waste and a tendency on the part of educators to isolate students from the adult world they will soon inhabit.

Although sensitivity was also largely omitted, educators may view sensitivity as a separate subject from solid waste. However, although other curricula in the schools may deal with the sensitivity issue, the effect of solid waste prevention and management on the planet's ecological balance must be noted in solid waste discussions and activities.

Recycling is quickly becoming an expected and often mandated behavior. The schools are an obvious place to reinforce social norms, via making posters or public service announcements about recycling efforts. Although reinforcing social norms is not a traditional objective of curriculum, activities promoting waste reduction as a social norm could become a part of curriculum that has as a goal the initiation of behavior change.

There are a number of ways to develop skills necessary for students to behave in an environmentally conscious manner. Case studies, issue investigation, and action research are tested teaching methods that effectively lead to skill development and behavior change.

Monroe and Kaplan (1988) suggested that case studies are an effective teaching method that lead to direct action. Case studies offer students an opportunity to see that others have made a difference within the context of a specific issue. Case studies are concrete, relevant, and 
often inspiring and can direct students toward successful action strategies.

Action research is a methodology whereby students engage in a problem-solving process while continually reflecting on their work and evaluating its effectiveness (Bull et al., 1988). It departs from the other methods in that students come to understand the situation through taking action, rather than first thoroughly understanding the problem and then considering an action.

Issue investigation, another methodology, consciously incorporates all the variables used in our evaluation except social norms. Research on this method found that issue investigation and action training "did foster overt, independent responsible environmental behavior" (Ramsey \& Hungerford, 1989). This methodology introduces students to an environmental issue and then develops skills in problem solving, evaluating, and action taking. Ramsey and Hungerford (1989) reported a significant increase in overt environmental behavior as well as significant changes in locus of control, knowledge (perceived and real) of environmental action skills, and perceived skill in the use of environmental action skills.

\section{Conclusion}

Experts project that 5 to $10 \%$ of our nation's waste can be reduced, 25 to $35 \%$ can be composted, and 40 to $45 \%$ can be recycled, leaving only 10 to $30 \%$ to be incinerated or deposited in landfills (Environmental Task Force, 1986). Education can serve as a tool to reach these goals. Yet after reviewing the existing curricula, we found that curricula designers and educators are isolated from researchers and their findings.

The following recommendations are aimed at increasing the effectiveness of our nation's solid waste curricula:

1. Educators should provide students with feedback on their contribution to the generation of solid waste and involve them in direct actions aimed at reducing their individual impact. Educators might also consider guiding student actions in arenas other than the classroom.

2. Educators should discuss attitudes surrounding solid waste.

3. Educators should learn how to use locus of control interventions and understand how education can change one's locus of control where such change is called for. They must explore ways of incorporating locus of control activities in their curricula.

4. Educators should incorporate visual aids and outdoor experiences in the curricula to illustrate the problems associated with solid waste and better sensitize students to the environment.

5. Schools should emphasize waste reduction as a social norm. If students learn about the solid waste problem in the classroom, discuss recycling and com- posting as possible solutions, and then go to the lunchroom where all leftover food and refuse is thrown together for disposal, they may become confused. Students should investigate and act on these issues.

6. Finally, educators and researchers must cooperate in order to explore and produce curricula that will effectively address the needs of our nation in the reduction of solid waste and the consumption of natural resources.

\section{APPENDIX}

A-Way With Waste. (1990). Washington State Department of Ecology, Waste Reduction, Recycling and Litter Control Program.

Classroom Activities. (1990). Maine Waste Management Agency, Office of Waste Reduction and Recycling.

Conserving Classroom. (1990). The Minnesota Environmental Education Board's Metro Regional Environmental Education Council.

Don't Waste Waste. (undated). Environmental Action Coalition.

4 th $R$ Recycling Curriculum. (1987). City and County of San Francisco's Solid Waste Management Program.

Here Today, Here Tomorrow: Revisited. (1989). New Jersey Department of Environmental Protection, Division of Solid Waste Management.

Let's Put Waste in Place. (1989). Klein, K. \& Shotkin, A. Phila-Pride, Inc.

Litter Control, Waste Management and Recycling Resource Unit, K-6. (1985). Louisiana State Department of Education.

Recycle Alaska. (1982). Alaska Department of Environmental Conservation.

Resource Recovery, Energy and Environment. (1980). Florida State Department of Education, Office of Environmental Education.

Solid Waste Activity Packet for Teachers. (1990). Illinois Department of Energy and Natural Resources.

Solution to Pollution. (1990). Indiana Department of Commerce, Division of Energy Policy.

Super Saver Investigators. (1988). Ohio Department of Natural Resources, Division of Litter Prevention and Recycling.

Waste A way. (1989). Vermont Institute of Natural Science.

\section{REFERENCES}

Braun, L., Ntshalintshali, C., \& McGurk, C. (1987). Chapter 6: Theoretical basis for program development. Environmental education for Swaziland. Unpublished master's thesis, University of Michigan.

Bull, J., Cromwell, M., Cwikiel, J. W., DiChiro, G., Guarino, J., Rathje, R., Stapp, W., Wals, A., \& Youngquist, M. (1988). Education in action: A community problem solving program for schools. Dexter, Michigan: Thomas-Shore.

De Young, R. (1988-1989). Exploring the difference between recyclers and non-recyclers: The role of information. Journal of Environmental Systems, 18(4):341-351.

Environmental Task Force. (1986). Shrinking the mountain of waste. Re:Sources, 6(3):5.

Hines, J. M., Hungerford, H., \& Tomera, A. N. (1986). Analysis and synthesis of research on responsible environmental behavior: $A$ meta-analysis. Journal of Environmental Education, 18(2):1-8.

Hungerford, H. R., Litherland, R. A., Peyton, R. B., Ramsey, J. M., Tomera, A. N., \& Volk, T. L. (1985). Investigating and evaluating environmental issues and actions skill development modules. Champaign, IL: Stipes Publishing Company.

Hungerford, H., \& Volk, T. (1990). Changing learner behavior through environmental education. Journal of Environmental Education, 21 (3):8-21.

Iozzi, L. A. (1989a). What research says to the educator: Part one. Journal of Environmental Education, 20(3):3-9.

Iozzi, L. A. (1989b). What research says to the educator: Part two. Journal of Environmental Education, 20(4):6-13. 
Monroe, M., \& Kaplan, S. (1988). When words speak louder than actions: Environmental problem solving in the classroom. Journal of Environmental Education, $19(3): 38-41$.

Office of Technology and Assessment. (1989). Facing America's trash. Washington, DC: U.S. Government Printing Office.

Powell, J. (1991). To each its own: Recent state recycling legislation. Resource Recycling, 10(10):32-35.

Ramsey, J. M., \& Hungerford, H. (1989). The effects of issue investigation and action training on environmental behavior in seventh grade students. Journal of Environmental Education, 20(4):29-34.

Sia, A. P., Hungerford, H., \& Tomera, A. N. (1985). Selected predictors of responsible environmental behavior: An analysis. Journal of Environmental Education, 17(2):31-40. 